\title{
A workplace well-being game intervention for health sciences librarians to address burnout
}

Tallie Casucci; Amy B. Locke; Autumn Henson; Fares Qeadan

See end of article for authors' affiliations.

\begin{abstract}
Objective: The authors measured burnout among health sciences librarians at their institution and determined whether a serious game intervention could improve personal and workplace well-being.

Methods: A modified American Medical Association Mini-Z burnout survey was administered to library faculty in 2016 and both library faculty and staff in 2017. A three-month team-based game was implemented and assessed as an intervention to improve well-being among library employees. After the game, the burnout survey was re-administered to employees in 2018.
\end{abstract}

Results: Library faculty scored poorly on burnout indicators, with $38 \%-73 \%$ of faculty reporting emotional exhaustion and $54 \%-91 \%$ reporting job-related stress over the years. In $2017,62 \%$ of library staff members reported experiencing burnout and 38\% indicated they felt a great deal of stress because of their jobs. Regarding the game intervention, $70 \%$ of post-game survey respondents reported that the game encouraged them to socialize with colleagues. Qualitative coding of survey responses resulted in 4 themes describing the most enjoyable aspects of the game: sociability, motivation, game play, and fun. Employees found that the game was a useful strategy for encouraging a more social culture with fun activities.

Conclusions: Similar to previous studies of librarians and health professionals, health sciences librarians at our institution experienced burnout. Although the game intervention did not significantly reduce burnout or increase job satisfaction, it improved collegiality and recognition. Therefore, a workplace well-being game can encourage team building but may not sufficiently address the root causes of health sciences librarian burnout.

\section{INTRODUCTION}

Burnout is defined as a "psychological syndrome of emotional exhaustion, depersonalization, and reduced personal accomplishment" [1]. Emotional exhaustion includes feelings of exhaustion and/or discouragement, which prompts actions to distance oneself emotionally and cognitively from one's work [2]. Depersonalization, or cynicism, is "negative, cynical attitudes and feelings about one's clients" [1], which also leads to distancing and considering others (e.g., colleagues and library users) as impersonal objects. The last element of burnout, reduced personal accomplishment or inefficacy, "refers to the tendency to evaluate oneself negatively...workers may feel unhappy about themselves and dissatisfied with their accomplishments on the job" [1].

These three psychological phenomena happen both in parallel and sequentially under various circumstances. As Maslach writes, "the lack of efficacy seems to arise more clearly from a lack of relevant resources, whereas exhaustion and cynicism emerge from the presence of work overload and social conflict" [2]. To measure the frequency and intensity of burnout, researchers have developed and validated multiple surveys to selfassess burnout risk, including the American Medical Association's (AMA's) Mini-Z survey [3, 4]. 
If burnout is one end of the continuum, the other end has been described by some authors as optimal workplace well-being or professional fulfillment [2,5]. Indeed, the World Health Organization defines burnout as "a syndrome conceptualized as resulting from chronic workplace stress that has not been successfully managed" [6] and mental health as "a state of well-being in which every individual realizes his or her own potential, can cope with the normal stresses of life, can work productively and fruitfully, and is able to make a contribution to her or his community" [7]. To Maslach, the antithesis of burnout is engagement [2]. Therefore, when considering burnout, it can be helpful to conceptualize its opposite state, for which Maslach and colleagues describe the three key components of vigor, dedication, and absorption [2].

In the library and information science (LIS) field, many studies have utilized a validated burnout survey tool [8-18], and chapter 2 of Ray's

dissertation contains a comprehensive review of LIS burnout literature [12]. Overall, these studies report low to moderate levels of burnout among librarians [8-18]. Burnout in the profession of health sciences librarians has not been investigated, although burnout among systematic review librarians, who likely were mostly health sciences librarians based on the study's recruitment methods, was recently assessed [18].

Burnout prevention interventions range from organization-level strategies to developing personal resilience among employees. The work by Maslach and colleagues on organizational-level predictors of workplace burnout provides a framework for creating organizational-level interventions [2], but these can be extremely challenging to implement. Data support both organization-directed and individual-focused approaches in health care settings [19]. Maslow's hierarchy of needs has also been used to consider target areas [20]. In the LIS field, burnout prevention interventions have not been created or assessed, although McCormack's 2013 book presents ideas for managing burnout at an organizational level in LIS settings [21]. Personal stories from LIS professionals present individualized approaches, such as saying "no," mediating, and changing jobs [22-26].

Serious games are unique interventions because they address purposes beyond mere entertainment, such as teaching or encouraging new skills, knowledge, or behaviors [27, 28]. Several review articles have shown that, overall, games have a positive impact on participants' engagement [29], knowledge acquisition [30,31], behavior [31], and motivation [31,32] and make "health activities fun, enjoyable, and understandable" [32]. For example, serious games have been used in corporate settings for skill or knowledge acquisition or health gamification [33, 34]. Games have not been used in the LIS field for employee interventions but have been discussed as materials for collection development and tools for education and outreach [35-39]. In the context of health sciences libraries, games are mainly for educating students [40-42].

The purpose of this study was to investigate health sciences librarians' burnout before and after a game intervention that was designed to decrease burnout and increase a sense of community.

\section{METHODS}

The University of Utah Resiliency Center conducts annual surveys to address burnout for Spencer $S$. Eccles Health Sciences Library (Eccles Library) employees. Eligibility to participate in the survey expanded from library faculty members in 2016 to both library faculty and staff in 2017. The Resiliency Center has collaborated with existing programs to implement targeted activities for health sciences librarians during this time frame. An Eccles Library faculty member was charged to develop and assess an intervention between the baseline and follow-up survey. As the Eccles Library had a history of utilizing, creating, and supporting serious games, the authors hypothesized that employees would be receptive to a serious game intervention.

\section{Survey instrument}

The survey instrument included select items from the AMA Mini-Z survey to assess burnout $[3,4]$. Eccles Library employees received the survey by email via SurveyMonkey. The survey included 7 out of 10 items originally on the AMA Mini-Z, including 5 -point Likert scale questions and a single-item burnout question, validated against the Maslach Burnout Inventory [43]. Categorical cut-offs were used to represent a binary measure of an employee's state, such as job satisfaction ("yes" or "no"), and their symptoms of burnout ("yes" or "no").

A baseline survey was administered to fifteen library faculty in May 2016 to June 2016 
(supplemental Appendix A). A follow-up survey was administered to fourteen library faculty and thirty-nine library staff in September to October 2017 (supplemental Appendix B). Due to extremely high burnout rates found among library employees in 2017, a shorter survey was re-administered to library employees in February 2018 (supplemental Appendix C). This second follow-up survey included questions from the modified AMA Mini-Z burnout survey, questions on depersonalization and meaning in work, and a depression screening (Patient Health Questionnaire-2). Additionally, four free-text response questions addressed next steps for the library moving forward. The raw data were shared with all library employees via email.

Afterward, the Resiliency Center's experts presented at a library employee meeting about available resources, facilitated group meetings on communication and team building, provided individual well-being and resiliency consultations, and hosted regular discussions with library leadership. Also, the Resiliency Center led discussions between Human Resources and library leadership, which resulted in an embedded human resources model.

\section{Statistical analysis of survey data}

The statistical package SAS 9.4 (SAS Institute, Cary, NC, USA) was used to perform statistical analyses. Demographic and AMA Mini-Z items are categorical variables and are reported as frequencies and relative frequencies (column percentages). Fisher's exact tests were used for demographic comparisons because the expected cell frequencies were low due to the small sample size, and Barnard's exact tests for risk difference were used to compare changes in the proportion of "yes" responses to items between years or between faculty and staff within the same year. Statistical significance was defined as $p<0.05$. Due to the small sample size and, hence, lack of statistical significance of comparisons, Cohen's $h$ is reported as a measure of effect size, with $\mathrm{h}=0.20,0.50$, and 0.80 indicating small, medium, and large sized effects, respectively.

\section{Game design and implementation}

After reviewing the baseline survey results and conducting informal interviews with a few library employees, we designed a game intervention, known as the "Wellness Game." Design box methodology [44] was used to design the game to target personal resilience and develop a culture of well-being. Additionally, the game design gave employees control over their participation, because control over their work and work environment were reported as low in the baseline survey results. Several decisions about game design were made to accomplish these goals (supplemental Appendix D).

After investigating the seven dimensions of wellness [45], we selected four areas for game points that touched on personal health and team collegiality: physical, mental (combined spiritual and intellectual wellness), social, and appreciation. Although appreciation is not a dimension of wellness [45], we recognized that some library employees only heard complaints and problems instead of a happy "Thanks!" from a patron, and a lack of appreciation was noted during the informal interviews with library employees.

During the informal interviews, we also found that library employees missed the "family feel" of the library and opportunities to get to know their colleagues. The game was designed to place a significant focus on this social category through diverse teams and physical game boards. The teams consisted of employees who worked in different departments and physical spaces. The final key game design component allowed flexibility; employees personalized the game with their own goals and interpretations of well-being activities. This decision was strongly supported by library administration, who did not want to further burden employees with additional work or projects. The metrics for determining the success of the game were participation, follow-up survey data, and a sense of community.

Prior to the start of the game, six team captains, who were charged with encouraging their teams, either volunteered or accepted the role when asked. After team captains were identified, all library employees were assigned to six teams. Employees received points for their teams for any activity related to appreciation, social, mental, or physical wellness. Each activity was worth one point, but some activities could receive a bonus point if the player did the activity with a colleague. For example, if someone went on a walk with a colleague, they could receive two points, one for physical wellness and another for social wellness. 
Each team had a game board that consisted of a large piece of paper divided into the four categories. All six game boards were attached to a bulletin board that was located in the employee break room to encourage interactions. Employees added tally marks to their teams' game boards in the appropriate category. Additionally, employees nominated others for an award, either serious or funny, through a short online survey. After nominating a colleague for an award, the employee was encouraged to give their team an appreciation point. A link to the survey and a reminder to participate in the Wellness Game were included in the library's daily email. At the game's conclusion, library employees celebrated with a potluck lunch and awards ceremony. A trophy was given to the team with the most points and was displayed in the employee break room. Awards were given to all nominees, and many award winners posted their certificates in their work spaces.

\section{Qualitative analysis of game evaluation survey}

At the end of the game, a paper-based evaluation survey containing ten multiple choice and free-text response questions (supplemental Appendix E) was given to library employees during an all-staff meeting. Employees had a week to complete the game evaluation survey. Qualitative data were thematically coded according to Strauss and Corbin's method [46].

\section{RESULTS}

Between 2016 and 2018, the University of Utah Resiliency Center conducted 3 surveys of Eccles Library employees. In 2016, only library faculty were eligible to participate in the survey, and the survey had an $80 \%$ response rate. In 2017, both library faculty and staff were eligible to participate, with response rates of $50 \%$ and $33 \%$, respectively. In 2018 , faculty and staff response rates were $93 \%$ and $54 \%$, respectively.

Analysis of baseline demographics of faculty (in 2016) and staff (in 2017) showed no significant differences between employee types in sex, age, or race (Table 1). However, there was a significant difference between the proportions of faculty versus staff who reported being of Latino or Hispanic origin ( $p=0.0391)$. Specifically, $67 \%$ faculty members reported that they were not of Latino or Hispanic origin (with the others preferring not to disclose this information), whereas $100 \%$ of staff reported that they were not of Latino or Hispanic origin.

\section{Faculty survey results}

Between 2016 and 2018, an increasing proportion of library faculty reported sufficient control over their workloads, corresponding with a decreasing proportion who reported burnout symptoms and job-related stress (Table 2). However, over time, fewer faculty reported overall job satisfaction, effectiveness of teamwork, and values aligned with leadership, and more reported a chaotic work atmosphere. These differences between years were not statistically significant, although the change in effective teamwork was associated with a largesized effect.

\section{Staff survey results}

Between 2017 and 2018, a decreasing proportion of library staff reported burnout, job-related stress, and a chaotic work atmosphere, and an increasing proportion reported sufficient control over their workload (Table 3). However, over time, fewer staff reported overall job satisfaction, values alignment with leadership, and effectiveness of teamwork. These differences between years were not statistically significant, although the changes in burnout and values alignment with leadership were associated with small-to-medium-sized effects.

\section{Faculty versus staff survey results}

In 2018, library staff scored better than library faculty on each of the AMA Mini-Z items, except the burnout question (Table 4). None of these differences were statistically significant, although differences in job satisfaction and job-related stress were associated with small-to-medium-sized effects. For the four open-ended questions concerning how the library should move forward to improve trust, success recognition, and support, employees provided suggestions related to transparent and open communication with less defensiveness, clearly defined strategic goals, and celebrations of success. 
Table 1 Baseline demographics for faculty and staff

\begin{tabular}{|c|c|c|c|c|c|}
\hline \multirow[b]{2}{*}{ Demographics } & \multicolumn{2}{|c|}{ Faculty (2016) } & \multicolumn{2}{|c|}{ Staff (2017) } & \multirow[b]{2}{*}{$p$-value } \\
\hline & $\mathbf{n}$ & $(\%)$ & $\mathbf{n}$ & $(\%)$ & \\
\hline Total & 12 & $(100.00 \%)$ & 13 & $(100.00 \%)$ & \\
\hline Sex & & & & & 0.0535 \\
\hline Male & 0 & $(-)$ & 5 & $(38.46 \%)$ & \\
\hline Female & 10 & $(83.33 \%)$ & 7 & $(53.85 \%)$ & \\
\hline Prefer not to answer & 1 & $(8.33 \%)$ & 1 & $(7.69 \%)$ & \\
\hline Race & & & & & 0.1488 \\
\hline White & 7 & $(58.33 \%)$ & 11 & $(84.62 \%)$ & \\
\hline Asian & 1 & $(8.33 \%)$ & 0 & $(-)$ & \\
\hline Other & 0 & $(-)$ & 1 & $(7.69 \%)$ & \\
\hline Prefer not to answer & 4 & $(33.33 \%)$ & 1 & $(7.69 \%)$ & \\
\hline Hispanic or Latino origin & & & & & 0.0391 \\
\hline No & 8 & $(66.67 \%)$ & 13 & $(100.00 \%)$ & \\
\hline Prefer not to answer & 4 & $(33.33 \%)$ & 0 & $(-)$ & \\
\hline \multicolumn{6}{|l|}{ Age (years) } \\
\hline $21-30$ & 2 & $(16.67 \%)$ & 1 & $(7.69 \%)$ & \\
\hline $31-40$ & 3 & $(25.00 \%)$ & 4 & $(30.77 \%)$ & \\
\hline $41-50$ & 5 & $(41.67 \%)$ & 2 & $(15.38 \%)$ & \\
\hline $51-64$ & 2 & $(16.67 \%)$ & 6 & $(46.15 \%)$ & \\
\hline
\end{tabular}

Table 2 Comparison of American Medical Association (AMA) Mini-Z items for faculty between 2016 and 2018

\begin{tabular}{|c|c|c|c|c|c|c|}
\hline \multirow[b]{2}{*}{ Items } & \multicolumn{2}{|c|}{2016} & \multicolumn{2}{|c|}{2018} & \multirow{2}{*}{$\begin{array}{c}\text { One-sided } \\
p \text {-value }\end{array}$} & \multirow[b]{2}{*}{ Cohen's h } \\
\hline & $\mathrm{n}$ & (\%) & $\mathbf{n}$ & $(\%)$ & & \\
\hline Overall satisfied with job* & & & & & 0.2792 & 0.291 \\
\hline Yes & 9 & (75.00\%) & 8 & $(61.54 \%)$ & & \\
\hline No & 3 & $(25.00 \%)$ & 5 & $(38.46 \%)$ & & \\
\hline Experiencing symptoms of burnout $†$ & & & & & 0.4740 & 0.065 \\
\hline Yes & 5 & $(41.67 \%)$ & 5 & $(38.46 \%)$ & & \\
\hline No & 7 & $(58.33 \%)$ & 8 & $(61.54 \%)$ & & \\
\hline Values align with leadership* & & & & & 0.2690 & 0.291 \\
\hline Yes & 9 & $(75.00 \%)$ & 8 & $(61.54 \%)$ & & \\
\hline No & 3 & $(25.00 \%)$ & 5 & $(38.46 \%)$ & & \\
\hline Teams work efficiently together & & & & & 0.1532 & 0.806 \\
\hline Yes & 11 & $(100.00 \%)$ & 11 & $(84.62 \%)$ & & \\
\hline No & 0 & $(-)$ & 2 & $(15.38 \%)$ & & \\
\hline Feeling great deal of job-related stress ${ }^{*}$ & & & & & 0.4449 & 0.090 \\
\hline Yes & 7 & $(58.33 \%)$ & 7 & $(53.85 \%)$ & & \\
\hline No & 5 & $(41.67 \%)$ & 6 & $(46.15 \%)$ & & \\
\hline Work atmosphere is hectic/chaotic§ & & & & & 0.2690 & 0.291 \\
\hline Yes & 3 & $(25.00 \%)$ & 5 & $(38.46 \%)$ & & \\
\hline No & 9 & $(75.00 \%)$ & 8 & $(61.54 \%)$ & & \\
\hline
\end{tabular}


Table 2 Comparison of American Medical Association (AMA) Mini-Z items for faculty between 2016 and 2018 (continued)

\begin{tabular}{|c|c|c|c|c|c|c|}
\hline \multirow[b]{2}{*}{ Items } & \multicolumn{2}{|c|}{2016} & \multicolumn{2}{|c|}{2018} & \multirow{2}{*}{$\begin{array}{c}\text { One-sided } \\
p \text {-value }\end{array}$} & \multirow[b]{2}{*}{ Cohen's h } \\
\hline & $\mathbf{n}$ & $(\%)$ & $\mathbf{n}$ & $(\%)$ & & \\
\hline Sufficient control over workload $\ddagger$ & & & & & 0.4409 & 0.229 \\
\hline Yes & 8 & $(66.67 \%)$ & 10 & (76.92\%) & & \\
\hline No & 4 & $(33.33 \%)$ & 3 & $(23.08 \%)$ & & \\
\hline Total & 12 & $(100.00 \%)$ & 13 & $(100.00 \%)$ & & \\
\hline
\end{tabular}

* Yes: Strongly agree/agree; No: Neither agree nor disagree/disagree/strongly disagree.

† Yes: I am definitely burning out and have one or more symptoms of burnout, e.g., emotional exhaustion./The symptoms of burnout that l'm experiencing won't go away./I think about work frustrations a lot./I feel completely burned out. I am at the point where I may need to seek help. No: I enjoy my work. I have no symptoms of burnout./I am under stress and don't always have as much energy as I did, but I don't feel burned out. ‡ Yes: Optimal/good/satisfactory; No: Marginal/poor.

$\S$ Yes: Hectic and chaotic/very busy; No: Busy, but reasonable/somewhat calm/calm.

Table 3 Comparison of AMA Mini-Z items for library staff between 2017 and 2018

\begin{tabular}{|c|c|c|c|c|c|c|}
\hline \multirow[b]{2}{*}{ Items } & \multicolumn{2}{|c|}{2017} & \multicolumn{2}{|c|}{2018} & \multirow{2}{*}{$\begin{array}{c}\text { One-sided } \\
p \text {-value }\end{array}$} & \multirow[b]{2}{*}{ Cohen's h } \\
\hline & $\mathrm{n}$ & $(\%)$ & n & $(\%)$ & & \\
\hline Overall satisfied with job* & & & & & 0.3727 & 0.213 \\
\hline Yes & 11 & $(84.62 \%)$ & 16 & $(76.19 \%)$ & & \\
\hline No & 2 & $(15.38 \%)$ & 5 & $(23.81 \%)$ & & \\
\hline Experiencing symptoms of burnout $\dagger$ & & & & & 0.1749 & 0.376 \\
\hline Yes & 8 & $(61.54 \%)$ & 9 & $(42.86 \%)$ & & \\
\hline No & 5 & $(38.46 \%)$ & 12 & $(57.14 \%)$ & & \\
\hline Values align with leadership* & & & & & 0.1488 & 0.425 \\
\hline Yes & 11 & $(84.62 \%)$ & 14 & $(66.67 \%)$ & & \\
\hline No & 2 & $(15.38 \%)$ & 7 & $(33.33 \%)$ & & \\
\hline Teams work efficiently togetherf & & & & & 0.7209 & 0.065 \\
\hline Yes & 12 & $(92.31 \%)$ & 19 & $(90.48 \%)$ & & \\
\hline No & 1 & $(7.69 \%)$ & 2 & $(9.52 \%)$ & & \\
\hline Feeling great deal of job-related stress* & & & & & 0.5131 & 0.008 \\
\hline Yes & 5 & $(38.46 \%)$ & 8 & $(38.10 \%)$ & & \\
\hline No & 8 & $(61.54 \%)$ & 13 & $(61.90 \%)$ & & \\
\hline Work atmosphere is hectic/chaotic§ & & & & & 0.4125 & 0.107 \\
\hline Yes & 5 & $(38.46 \%)$ & 7 & $(33.33 \%)$ & & \\
\hline No & 8 & $(61.54 \%)$ & 14 & $(66.67 \%)$ & & \\
\hline Sufficient control over workloadł & & & & & 0.6134 & 0.031 \\
\hline Yes & 11 & $(84.62 \%)$ & 18 & $(85.71 \%)$ & & \\
\hline No & 2 & $(15.38 \%)$ & 3 & $(14.29 \%)$ & & \\
\hline Total & 13 & $(100.00 \%)$ & 21 & $(100.00 \%)$ & & \\
\hline
\end{tabular}

* Yes: Strongly agree/agree; No: Neither agree nor disagree/disagree/strongly disagree.

† Yes: I am definitely burning out and have one or more symptoms of burnout, e.g., emotional exhaustion./The symptoms of burnout that l'm experiencing won't go away./I think about work frustrations a lot./I feel completely burned out. I am at the point where I may need to seek help. No: I enjoy my work. I have no symptoms of burnout./I am under stress and don't always have as much energy as I did, but I don't feel burned out. ‡ Yes: Optimal/good/satisfactory; No: Marginal/poor.

$\S$ Yes: Hectic and chaotic/very busy; No: Busy, but reasonable/somewhat calm/calm. 
Table 4 Comparison of AMA Mini-Z items between library faculty and staff in 2018

\begin{tabular}{|c|c|c|c|c|c|c|}
\hline \multirow[b]{2}{*}{ Items } & \multicolumn{2}{|c|}{ Faculty } & \multicolumn{2}{|c|}{ Staff } & \multirow{2}{*}{$\begin{array}{c}\text { One-sided } \\
p \text {-value }\end{array}$} & \multirow[b]{2}{*}{ Cohen's h } \\
\hline & $\mathbf{n}$ & $(\%)$ & $\mathbf{n}$ & $(\%)$ & & \\
\hline Overall satisfied with job* & & & & & 0.2595 & 0.318 \\
\hline Yes & 8 & $(61.54 \%)$ & 16 & $(76.19 \%)$ & & \\
\hline No & 5 & $(38.46 \%)$ & 5 & $(23.81 \%)$ & & \\
\hline Experiencing symptoms of burnout $†$ & & & & & 0.4567 & 0.090 \\
\hline Yes & 5 & $(38.46 \%)$ & 9 & $(42.86 \%)$ & & \\
\hline No & 8 & $(61.54 \%)$ & 12 & $(57.14 \%)$ & & \\
\hline Values align with leadership* & & & & & 0.7506 & 0.107 \\
\hline Yes & 8 & $(61.54 \%)$ & 14 & $(66.67 \%)$ & & \\
\hline No & 5 & $(38.46 \%)$ & 7 & $(33.33 \%)$ & & \\
\hline Teams work efficiently togetherł & & & & & 0.4125 & 0.179 \\
\hline Yes & 11 & $(84.62 \%)$ & 19 & $(90.48 \%)$ & & \\
\hline No & 2 & $(15.38 \%)$ & 2 & $(9.52 \%)$ & & \\
\hline Feeling great deal of job-related stress* & & & & & 0.2958 & 0.317 \\
\hline Yes & 7 & $(53.85 \%)$ & 8 & $(38.10 \%)$ & & \\
\hline No & 6 & $(46.15 \%)$ & 13 & $(61.90 \%)$ & & \\
\hline Work atmosphere is hectic/chaotic $\S$ & & & & & 0.4125 & 0.107 \\
\hline Yes & 5 & $(38.46 \%)$ & 7 & $(33.33 \%)$ & & \\
\hline No & 8 & $(61.54 \%)$ & 14 & $(66.67 \%)$ & & \\
\hline Sufficient control over workload $\ddagger$ & & & & & 0.4177 & 0.227 \\
\hline Yes & 10 & $(76.92 \%)$ & 18 & $(85.71 \%)$ & & \\
\hline No & 3 & $(23.08 \%)$ & 3 & $(14.29 \%)$ & & \\
\hline Total & 13 & $(100.00 \%)$ & 21 & $(100.00 \%)$ & & \\
\hline
\end{tabular}

* Yes: Strongly agree/agree; No: Neither agree nor disagree/disagree/strongly disagree.

† Yes: I am definitely burning out and have one or more symptoms of burnout, e.g., emotional exhaustion./The symptoms of burnout that I'm experiencing won't go away./I think about work frustrations a lot./I feel completely burned out. I am at the point where I may need to seek help. No: I enjoy my work. I have no symptoms of burnout./I am under stress and don't always have as much energy as I did, but I don't feel burned out. ‡ Yes: Optimal/good/satisfactory; No: Marginal/poor.

$\S$ Yes: Hectic and chaotic/very busy; No: Busy, but reasonable/somewhat calm/calm.

\section{Qualitative analysis of game evaluation survey}

Based on post-game survey data, the game design gave players control and improved team socializing. Three specific quotes from the post-game survey highlighted this flexibility and control: "I did this anyway, but it was nice to get 'credit' for doing wellness activities"; "My own goals - no additional imposed goals"; and "Recording points for things I was doing anyways." The social elements were specifically highlighted in the game design through diverse teams, physical score boards, and bonus points to address the concern of team collegiality. In the post-game survey, employees noted that they "met a few new people" and "Once in [the] staff lounge [I] was asked to join conversation." Additionally, $70 \%$ of employees indicated that the game encouraged them to socialize with others.

Throughout the game, some team captains organized social events to garner bonus points. For example, a team "walked 11 stairs at 11 a.m." We observed employees eating lunch together and walking around the library for quick discussions. Two team captains organized after-work hikes on Thursdays, and an estimated 6 employees participated. Twelve award nominations were submitted to the online survey. During the potluck lunch and awards ceremony, the winning team was presented with a large personalized trophy. The 
winning team had 7,312 points, beating the other teams by 5,047 points.

Thirty out of the 59 employees (50.85\%) completed the post-game survey. A total of 21 employees recorded their activity daily, 2-3 times per week, or weekly; whereas 2 employees recorded monthly and 5 employees recorded only once. More than half of employees found that the game encouraged them in the appreciation, physical, and social categories (Figure 1). After coding the qualitative data for "What did you enjoy most about the game?" free-text response question, 4 categories emerged: social, motivation, gameplay, and fun (Table 5). After coding the qualitative data for "What did you enjoy least about the game?" free-text response question, 3 categories emerged: game points, team engagement, and game duration (Table 6).

Figure 1 Number of employees reporting that the game encouraged them to do something for their wellness

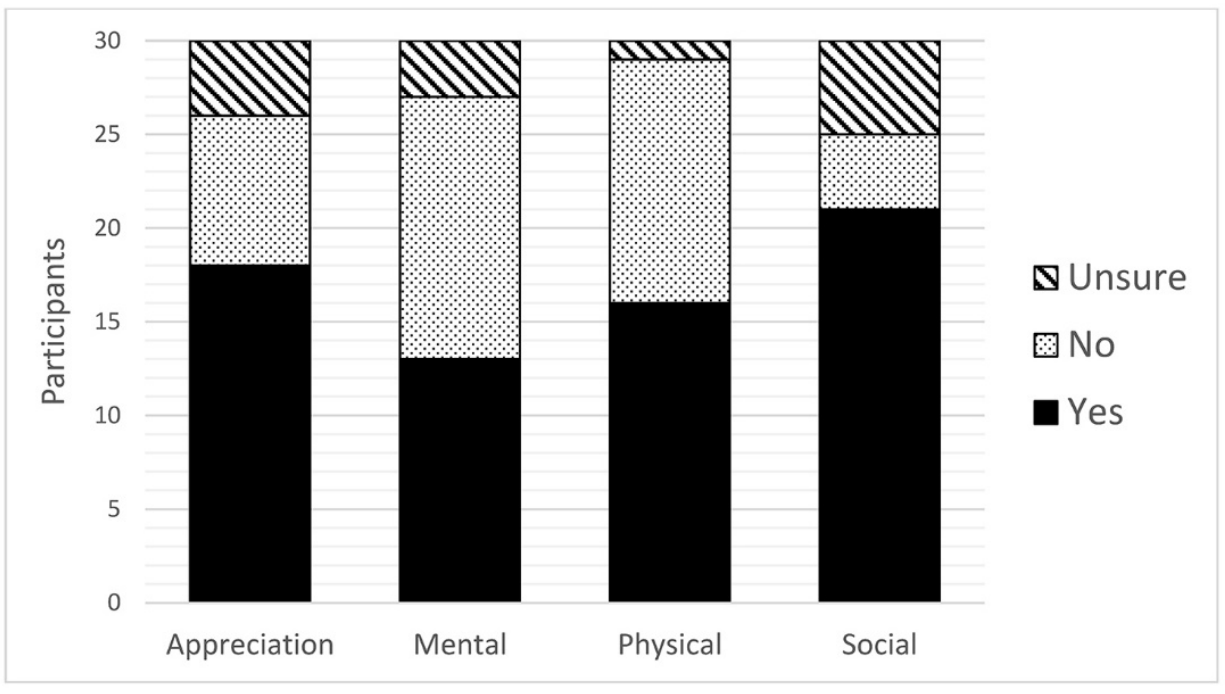

Table 5 Qualitative categories for “What did you enjoy most about the game?"

\begin{tabular}{|c|c|c|c|}
\hline Category & $\mathbf{n}$ & Definition & Exemplar quotes \\
\hline Social & 19 & $\begin{array}{l}\text { Comments about the team-based game } \\
\text { approach and the social and appreciation } \\
\text { game components. }\end{array}$ & $\begin{array}{l}\text { "I think this helped encourage people to } \\
\text { socialize more, which was nice," and "Team } \\
\text { building." }\end{array}$ \\
\hline Motivation & 6 & $\begin{array}{l}\text { Comments about how the game motivated } \\
\text { them to learn about wellness or improve their } \\
\text { wellness. }\end{array}$ & $\begin{array}{l}\text { "Made me more aware of these health } \\
\text { aspects" and "The motivation to make } \\
\text { healthy choices." }\end{array}$ \\
\hline Gameplay & 6 & $\begin{array}{l}\text { Comments concerning elements about } \\
\text { gameplay that they enjoyed, such as no } \\
\text { additional work, personalized goals, and } \\
\text { habit recognition. }\end{array}$ & $\begin{array}{l}\text { "Easy. No additional work," and "Being able } \\
\text { to think and track your wellness activities } \\
\text { that you may or may not realize you do every } \\
\text { day." }\end{array}$ \\
\hline Fun & 5 & Comments about fun aspect of the game. & "It... was fun. Thanks!" \\
\hline
\end{tabular}


Table 6 Qualitative categories for "What did you enjoy least about the game?"

\begin{tabular}{|c|c|c|c|}
\hline Category & $\mathbf{n}$ & Definition & Exemplar quotes \\
\hline Game points & 10 & $\begin{array}{l}\text { Comments concerning the tracking system } \\
\text { and a better defined point system. }\end{array}$ & $\begin{array}{l}\text { "Tedious record keeping," and "I think there } \\
\text { could have been more defined way/types of } \\
\text { points and maybe a cap per day," and } \\
\text { "Maybe online tracking with a dashboard of } \\
\text { how teams are doing." }\end{array}$ \\
\hline $\begin{array}{l}\text { Team } \\
\text { engagement }\end{array}$ & 7 & Comments focused on low team engagement. & $\begin{array}{l}\text { "My team did not do anything together," "I } \\
\text { did not hear from my team captain at all," } \\
\text { and "Encouraging team members to } \\
\text { participate," which focused on low team } \\
\text { engagement. }\end{array}$ \\
\hline Game duration & 7 & $\begin{array}{l}\text { Comments stated that the game lasted too } \\
\text { long. }\end{array}$ & $\begin{array}{l}\text { "I thought it continued too long - }[\mathrm{I}] \text { lost } \\
\text { interest in recording," and "Waiting three } \\
\text { months for the 'end.' Perhaps evaluating after } \\
\text { one month and then switching groups would } \\
\text { help keep motivation up." }\end{array}$ \\
\hline
\end{tabular}

\section{DISCUSSION}

The game intervention did not significantly impact burnout and job satisfaction but did create a more social environment and stimulated library employees to participate in wellness activities. To our knowledge, this was the first LIS study in which the same population of librarians was surveyed multiple times with validated burnout items and in which an intervention was created and assessed between surveys. Our results demonstrated that a game intervention might not be able to address the root causes of burnout but could encourage a more social environment.

The metrics for determining game success were the Resiliency Center's survey data, game participation, and a sense of community. According to the Resiliency Center's survey data, the game did not improve personal resilience or burnout.

Participation was difficult to determine, as the postgame survey response was low $(50.8 \%)$, and 7 employees indicated that they tracked their points only once a month or once at all. As 1 employee noted in the post-game survey, a "drop in participation" occurred near the end of the game. However, a sense of community was clearly developed during the course of the game. In the post-game survey, $70 \%$ indicated that the game encouraged them to do something for their social well-being. Additionally, 53\% of the free-text comments for the question "What did you enjoy most about the game?" were coded to the social category. As mentioned earlier, the library employees ate lunch together, organized after-work hikes, and participated in more active meetings. Most employees (72\%) indicated that they would play the game again. Therefore, the game met at least 1 of the 3 success metrics.

As LIS games primarily focus on education, health and corporate games were worth examining. One previous study at a corporate organization utilizing a team sport intervention to improve employee physical health and interpersonal communication found that employees who participated in the team sport intervention showed a $3 \%$ increase in interpersonal communication [33]. Similarly, our post-game survey respondents stated that they "met a few new people" and "Once in [the] staff lounge [I] was asked to join conversation." Thus, both the previously described team sport intervention and our game increased socializing and communication among employees. As one postgame survey respondent stated, "There was more socializing. More 'together' lunches. Some fun 'walks' [and] 'hikes' planned which build friendship." Interestingly, another study on a weight loss mobile application (app) intervention found that the social support element encouraged more weight loss than the gamification element of the app [47]. These findings supported our decision in designing the game to focus on team collegiality and social aspects. 
In addition to team collegiality and communication, we designed the game to allow flexibility due to concerns over faculty's perceived lack of control over their workloads in the 2016 burnout survey. Similar to Shahrestani and colleagues' health app intervention, we offered more flexibility for participants to record any activity [34]. Shahrestani and colleagues stated:

Unfortunately, daily steps only give a narrow view on activity levels...it may be detrimental in less controlled settings such as corporate environments where people are recruited to join health games and competitions. In such a setting, people who perform frequent swimming (or biking,...) activities would find it quite unfair if less fit challenge participants would systematically win the corporate challenges simply because they happen to make more steps per day. [34]

During the initial informal interviews, some library employees mentioned daily step count challenges as a possible intervention, which are very common in workplace settings. Shahrestani and colleagues' argument against just daily step counts [34] confirmed our reservations about daily step counts. Additionally, by avoiding required expectations and activities with the game, employees had flexibility and control over their involvement in activities. We anticipated that some employees would not engage or participate regardless of the intervention. By not being forced to participate or achieve specific requirements, such as step counts, employees maintained flexibility and control over their activities.

Another interesting finding in the present and previous studies were the differences in burnout depending on employee status. Eccles Library faculty experienced emotional exhaustion at a higher rate than library staff. Similarly, Shabani and colleagues found that employees with an LIS degree had higher levels of emotional exhaustion than library employees without an LIS degree [15]. At Eccles Library, an employee's status is usually determined by their education, so all library faculty have a master's degree in LIS, whereas staff rarely have an advanced degree in LIS. Thus, including a question concerning Eccles Library employees' highest level of education would have been helpful for making comparisons to Shabani and colleagues' findings. Additionally, Togia found that temporary employees experienced higher levels of emotional exhaustion than employees in permanent positions
[13]. As a few full-time Eccles Library employees were on year-to-year contracts, it would be interesting to see if part-time and contract-based employees would also report higher levels of emotional exhaustion, similar to Togia's findings.

This study found more differences in employee status (faculty versus staff) and their work enjoyment, such as happiness at work, levels of stress, chaos, and values aligned with leaders. Despite working at the same library, the employee's status of faculty or staff influenced their satisfaction and fulfillment. The library faculty experienced a challenging work environment in 2017: five junior faculty left and two senior faculty members retired in less than one year. These numbers indicated that the leadership uncertainty and faculty turnover during 2017 might have impacted library faculty more than staff.

A variety of factors contribute to employee wellbeing, including both long-standing, predictable factors such as workload, layout of physical space, and job duties $[1,2,21]$ and short-term factors such as leadership or employee turnover and group conflict [48-50]. Thus, addressing one factor in isolation may not be sufficient to change overall workplace well-being, thus limiting the impact of a targeted intervention. The lack of a major response to the game despite positive comments from participants, along with the reduction in burnout in February 2018 following a broader set of interventions, suggests a multifactorial approach was needed. Also, although games can be a useful strategy for encouraging a more social culture with fun activities, they have some potential limitations, including not addressing the root causes of burnout, taking too long, and having low rates of engagement. As noted by other studies, workplace demands and culture (e.g., personal, organizational, societal) may be barriers to participating in wellbeing activities at work [33, 51].

Employee burnout remains a concern at our library. However, although the game intervention did not improve burnout or job satisfaction, it did improve collegiality and recognition among employees. Thus, a game can encourage teambuilding but may not sufficiently address the root causes of burnout among health sciences librarians. LIS professionals and researchers should investigate Maslach's organizational level predictors of burnout $[2,21]$ to implement and assess other interventions 
aimed at addressing librarian burnout. A focus on vigor, dedication, and absorption may increase engagement and well-being [2]. A recent article uses Maslow's hierarchy of needs to describe an approach to interventions [52]. Individuals experiencing burnout should seek help from a health professional for guidance. There are increasing resources available to help institutions and individuals approach this situation, including the National Academy of Medicine Action Collaborative on Clinician Well-Being and Resilience [53] and the National Network of Libraries of Medicine's Wellness in the Library Workplace [54].

\section{ACKNOWLEDGMENTS}

We thank Robin Marcus, chief wellness officer; the Resiliency Center team, including Whitney Werner; and the Eccles Library employees who advocated for the game, including Donna Baluchi, Sarah Dickey, Peter Strohmeyer, and Jessi Van Der Volgen, AHIP.

\section{REFERENCES}

1. Maslach C, Jackson SE, Leiter MP, Schaufeli WB, Schwab RL. Maslach burnout inventory. Palo Alto, CA: Consulting Psychologists Press; 1986. 34 p.

2. Maslach C, Schaufeli WB, Leiter MP. Job burnout. Annu Rev Psychol. 2001;52(1):397-422.

3. Dolan ED, Mohr D, Lempa M, Joos S, Fihn SD, Nelson KM, Helfrich CD. Using a single item to measure burnout in primary care staff: a psychometric evaluation. J Gen Intern Med. 2015 May;30(5):582-7.

4. American Medical Association. StepsForward: improve physician satisfaction and patient outcomes [Internet]. Chicago, IL: The Association [cited 31 Jul 2020]. $<$ https:/ / edhub.ama-assn.org/stepsforward/module/2702509>.

5. Grawitch MJ, Ballard DW, Erb KR. Work and wellbeing: creating a psychologically healthy workplace. In: Leiter MP, Cooper CL, ed. The Routledge companion to wellbeing at work. 1st ed. New York, NY: Routledge; 2017. p. 249-68.

6. World Health Organization. Burn-out an "occupational phenomenon": international classification of diseases World Health Organization [Internet]. Geneva, Switzerland: The Organization [updated 28 May 2019; cited 8 Jul 2019]. $<$ https://www.who.int/mental_health/evidence/burnout/en/>.

7. World Health Organization. Mental health [Internet]. Geneva, Switzerland: The Organization [updated Aug 2014; cited 8 Jul 2019]. $\leq$ https://www.who.int/features/factfiles/mental_health Len/>.

8. Smith NM, Nielsen LF. Burnout: a survey of corporate librarians. Special Libr. 1984 Jul;75(3):221-7.
9. Birch N. Perceived role conflict, role ambiguity, and reference librarian burnout in public libraries. Libr Inf Sci Res. 1986 Jan-Mar;8(1):53-65.

10. Nelson VC. Burnout: a reality for law librarians. Law Libr J. 1987;79:267.

11. Affleck MA. Burnout among bibliographic instruction librarians. Libr Inf Sci Res. 1996 Spring;18(2):165-83.

12. Ray B. An assessment of burnout in academic librarians in America using the Maslach Burnout Inventory (the MBI) [dissertation]. New Brunswick, NJ: Rutgers; 2002. 90 p.

13. Togia A. Measurement of burnout and the influence of background characteristics in Greek academic librarians. Libr Manag. 2005; 26(3):130-8.

14. Siamian H, Shahrabi A, Vahedi M, Rad A, Majid A, Cherati JY. Stress and burnout in libraries \& information centers. In: Proceedings of Asia-Pacific Conference on Library and Information Education and Practice; Singapore: The Conference; 3-6 Apr 2006.

15. Shabani A, Aderyani RR, Abedi M, Naderi F. Investigating the occupational burnout of librarians in University of Isfahan. Int J Inf Sci Manag. 2012 Jul-Dec;10(2):117-33.

16. Harwell K. Burnout and job engagement among business librarians. Libr Leadersh Manag. 2013;27(1/2).

17. Lindén M, Salo I, Jansson A. Organizational stressors and burnout in public librarians. J Librariansh Inf Sci. 2018;50(2):199-204.

18. Demetres MR, Wright DN, DeRosa AP. Burnout among medical and health sciences information professionals who support systematic reviews: an exploratory study. J Med Libr Assoc. 2020 Jan;108(1):89-97. DOI: http://dx.doi.org/10.5195/imla.2020.665.

19. Panagioti M, Panagopoulou E, Bower P, Lewith G, Kontopantelis E, Chew-Graham C, Dawson S, Van Marwijk H, Geraghty K, Esmail A. Controlled interventions to reduce burnout in physicians: a systematic review and meta-analysis. JAMA Internal Med. 2017 Feb;177(2):195-205.

20. Trockel M, Bohman B, Lesure E, Hamidi MS, Welle D, Roberts L, Shanafelt T. A brief instrument to assess both burnout and professional fulfillment in physicians: reliability and validity, including correlation with selfreported medical errors, in a sample of resident and practicing physicians. Acad Psychiatry. 2018 Feb;42(1):11-24.

21. McCormack N. Managing burnout in the workplace: a guide for information professionals. Philadelphia, PA: Chandos Publishing, Woodhead Publishing; 2013. 222 p.

22. Harwell K. Burnout strategies for librarians. J Bus Finance Librariansh. 2008;13(3):379-90.

23. Hines SS. Avoiding and recovering from burnout. In: Smallwood C, Wade LB, eds. Job stress and the librarian: coping strategies from the professionals. Jefferson, NC: McFarland \& Company; 2013. p. 36-70.

24. Kennedy T. The path on the road to burnout. J Hosp Librariansh. 2001;1(4):93-8. 
25. Sheesley DF. Burnout and the academic teaching librarian: an examination of the problem and suggested solutions. J Acad Libr. 2001 Nov;27(6):447-51

26. Caputo JS. Stress and burnout in library service. Phoenix, AZ: Oryx Press; 1991. 172 p.

27. Susi T, Johannesson M, Backlund P. Serious games: an overview. Skövde, Sweden: University of Skövde; 2007 Feb 5. 28 p. Report no.: HS-IKI-TR-07-001.

28. Marsh T. Serious games continuum: between games for purpose and experiential environments for purpose. Entertain Comput. 2011;2(2):61-8.

29. Boyle EA, Connolly TM, Hainey T, Boyle JM. Engagement in digital entertainment games: a systematic review. Comput Human Behav. 2012;28(3):771-80.

30. Boyle EA, Hainey T, Connolly TM, Gray G, Earp J, Ott M, Lim T, Ninaus M, Ribeiro C, Pereira J. An update to the systematic literature review of empirical evidence of the impacts and outcomes of computer games and serious games. Comput Educ. 2016 Mar;94:178-92.

31. Connolly TM, Boyle EA, MacArthur E, Hainey T, Boyle JM. A systematic literature review of empirical evidence on computer games and serious games. Comput Educ. 2012 Sep;59(2):661-86.

32. Sardi L, Idri A, Fernandez-Aleman JL. A systematic review of gamification in e-health. J Biomed Inform. 2017 Jul;71:31-48.

33. Brinkley A, McDermott H, Grenfell-Essam R, Munir F. It's time to start changing the game: a 12-week workplace team sport intervention study. Sports Med Open. 2017 Aug;3(1):30.

34. Shahrestani A, Van Gorp P, Le Blanc P, Greidanus F, de Groot K, Leermakers J. Unified health gamification can significantly improve well-being in corporate environments. Conf Proc IEEE Eng Med Biol Soc. 2017 Jul;2017:4507-11.

35. Nicholson S. Playing in the past: a history of games, toys, and puzzles in North American libraries. Libr Q. 2013 Oct;83(4):341-61.

36. Robson D. New directions for academic video game collections: strategies for acquiring, supporting, and managing online materials. J Acad Libr. 2012 Mar;38(2):79-84.

37. Markey K, Swanson F, Jenkins A, Jennings B, Jean BS, Rosenberg V, Xingxing Y, Frost R. Will undergraduate students play games to learn how to conduct library research? J Acad Libr. 2009 Jul;35(4):303-13.

38. Vanden Elzen AM, Roush J. Brawling in the library: gaming programs for impactful outreach and instruction at an academic library. Libr Trends. 2013;61(4):802-13.

39. Bishoff C, Farrell SL, Neeser AE. Outreach, collaboration, collegiality: evolving approaches to library video game services. J Libr Innovation. 2015;6(1):92-109.
40. Gleason AW. RELM: developing a serious game to teach evidence-based medicine in an academic health sciences setting. Med Ref Serv Q. 2015;34(1):17-28.

41. Blevins AE, Kiscaden E, Bengtson J. Courting apocalypse: creating a zombie-themed evidence-based medicine game. Med Ref Serv Q. 2017 Oct-Dec;36(4):313-22.

42. Brigham TJ. An introduction to gamification: adding game elements for engagement. Med Ref Serv $Q$. 2015;34(4):471-80.

43. Rohland BM, Kruse GR, Rohrer JE. Validation of a singleitem measure of burnout against the Maslach burnout inventory among physicians. Stress Health. 2004;20(2):75-9.

44. Altizer RA, Zagal JP. Designing inside the box or pitching practices in industry and education. In: Proceedings of the 2014 DiGRA International Conference; Snowbird, UT; 3-6 Aug 2014. Digital Games Research Association.

45. University of California Riverside, Human Resources. Seven dimensions of wellness. Riverside, CA: Regents of the University of California.

46. Strauss A, Corbin J. Basics of qualitative research: grounded theory procedures and techniques. Newbury Park, CA: Sage Publications; 1990.270 p.

47. Kurtzman GW, Day SC, Small DS, Lynch M, Zhu J, Wang W, Rareshide CAL, Patel MS. Social incentives and gamification to promote weight loss: the LOSE IT randomized, controlled trial. J Gen Intern Med. 2018 Oct;33(10):1669-75

48. Kendrick KD. The low morale experience of academic librarians: a phenomenological study. J Libr Admin. 2017;57(8):846-78.

49. Ortega A. Academic libraries and toxic leadership [dissertation]. San Diego, CA: University of San Diego; 2019. $150 \mathrm{p}$.

50. Freedman S, Vreven D. Workplace incivility and bullying in the library: perception or reality? Coll Res Libr. 2017 Nov;77(6):727-48.

51. Brinkley A, Freeman J, McDermott H, Munir F. What are the facilitators and obstacles to participation in workplace team sport? a qualitative study. AIMS Public Health. 2017 Feb 23;4(1):94-126.

52. Shapiro DE, Duquette C, Abbott LM, Babineau T, Pearl A, Haidet $P$. Beyond burnout: a physician wellness hierarchy designed to prioritize interventions at the systems level. Am J Med. 2019 May;132(5):556-63.

53. National Academy of Medicine. Action collaborative on clinician well-being and resilience [Internet]. Washington, DC: The Academy [updated 2018; cited 15 Feb 2019]. $<$ https:// nam.edu/initiatives/clinician-resilience-andwell-being/>

54. National Network of the Libraries of Medicine. Wellness in the library workplace [Internet]. Bethesda, MD: The Network [updated 2019; cited 3 May 2019]. <https://nnlm.gov/classes/wellness-library-workplace> 
sca

\section{SUPPLEMENTAL FILES}

- Appendix A: University of Utah health sciences faculty wellness needs assessment: survey of faculty wellness

- Appendix B: University of Utah health sciences faculty wellness needs assessment: survey of faculty wellness, fall 2017

- Appendix C: Spencer S. Eccles Health Sciences Library survey, winter 2018

- Appendix D: Design box for the Spencer S. Eccles Health Sciences Library (EHSL) Wellness Game

- Appendix E: Post-assessment of the Spencer S. Eccles Health Sciences Library Wellness Game

\section{AUTHORS' AFFILIATIONS}

Tallie Casucci, tallie.casucci@utah.edu, https://orcid.org/00000001-6311-9613, J. Willard Marriott Library, University of Utah, Salt Lake City, UT

Amy B. Locke, amy.locke@hsc.utah.edu, Family and Preventive Medicine, University of Utah, Salt Lake City, UT

Autumn Henson, autumn.henson@utah.edu, Public Health, University of Utah, Salt Lake City, UT

Fares Qeadan, fares.qeadan@utah.edu, https://orcid.org/00000002-3376-220X, School of Medicine, University of Utah, Salt Lake City, UT

Received May 2019; accepted May 2020

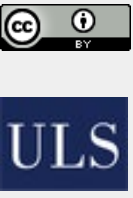

Articles in this journal are licensed under a Creative Commons Attribution 4.0 International License.

This journal is published by the University Library System of the University of Pittsburgh as part of its D-Scribe Digital Publishing Program and is cosponsored by the University of Pittsburgh Press. 